\title{
Abriendo Futuros: A program for rural indigenous girls in Yucatan, Mexico
}

\author{
Fabiola Romero \\ Population Council \\ Ludivine Cicolella \\ Population Council \\ Silvana Larrea \\ Population Council \\ A. Fallone \\ Isabel Vieitez Martínez \\ Population Council
}

Follow this and additional works at: https://knowledgecommons.popcouncil.org/departments_sbsr-pgy

Part of the Demography, Population, and Ecology Commons, Family, Life Course, and Society Commons, Gender and Sexuality Commons, Indigenous Education Commons, International Public Health Commons, and the Medicine and Health Commons

How does access to this work benefit you? Let us know!

\section{Recommended Citation}

Romero, Fabiola, Ludivine Cicolella, Silvana Larrea, A. Fallone, and Isabel Vieitez Martínez. 2020.

"Abriendo Futuros: A program for rural indigenous girls in Yucatan, Mexico," Policy brief. Mexico City:

Population Council. 


\section{ABRIENDO FUTUROS A PROGRAM FOR RURAL INDIGENOUS GIRLS IN YUCATAN, MEXICO}

\section{Mexico is a multicultural country with 68 different indigenous groups. There are approximately 12.2 million indigenous people living in Mexico (10.1\% of the population), of which $19.6 \%$ are children aged 6 to 14 years and $6.2 \%$ are adolescents aged 15 to 17 years. ${ }^{1}$}

The State of Yucatan, with a population of approximately 2.1 million people (1.8\% of Mexico's population), is one of the poorest in the country. Approximately $46 \%$ of the population live under the poverty line and $60 \%$ of Yucatan municipalities are identified as being highly marginalized. The illiteracy rate among those aged 15 years and older is $7.4 \%$, which is $2 \%$ above the national percentage..$^{2-4}$ Of all Mexican states, Yucatan has the highest proportion of indigenous population versus nonindigenous population in the country $(50.2 \%) .^{1}$

Girls living in indigenous communities are exposed to social determinants that exacerbate preexisting conditions related to inequality and discrimination, such as poverty; violence; inequitable gender norms; education; teenage pregnancy; child, early, or forced marriages and unions (CEFMU); unpaid care and domestic work; and lack of agency in decision-making (5).

Use of contraceptive methods is low among Mexican indigenous women; while 73 out of every 100 nonindigenous cohabiting women use some kind of contraception, only 59 out of 100 indigenous women use contraception, placing them at higher risk for an unplanned pregnancy. Approximately $40 \%$ of the municipalities $(n=106)$ in Yucatan have teenage pregnancy rates above the national average levels (77.1 per 1,000 births). In Yucatan, 12\% of women reported becoming sexually active before the age of $15,34 \%$ of girls united or got married before the age of 18 (10\% before the age of 15$)$, and $13 \%$ of adolescent girls aged 15-19 years reported ever being pregnant at this age. ${ }^{6}$

As for education quality indicators, indigenous preschools and elementary schools (versus nonindigenous schools) have younger and less prepared teachers, poorer infrastructure (e.g., construction material, desks, access to computers and internet), and poorer educational attainment results in Spanish, math, and natural science. This is reflected in a higher dropout rate in middle schools and high schools in indigenous municipalities versus nonindigenous municipalities, as well as a lower return in education for indigenous

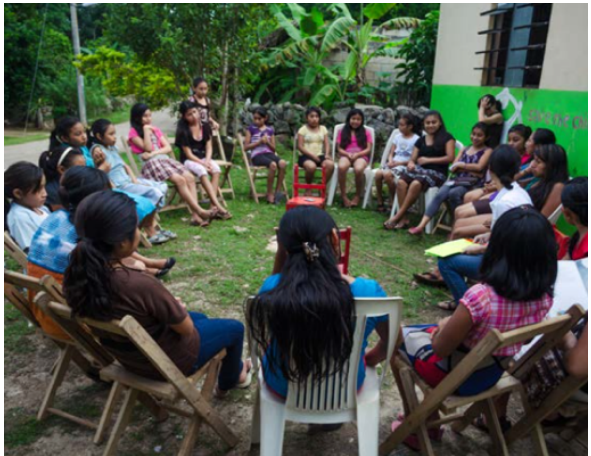

Abriendo Futuros weekly workshop. Yucatan, 2017

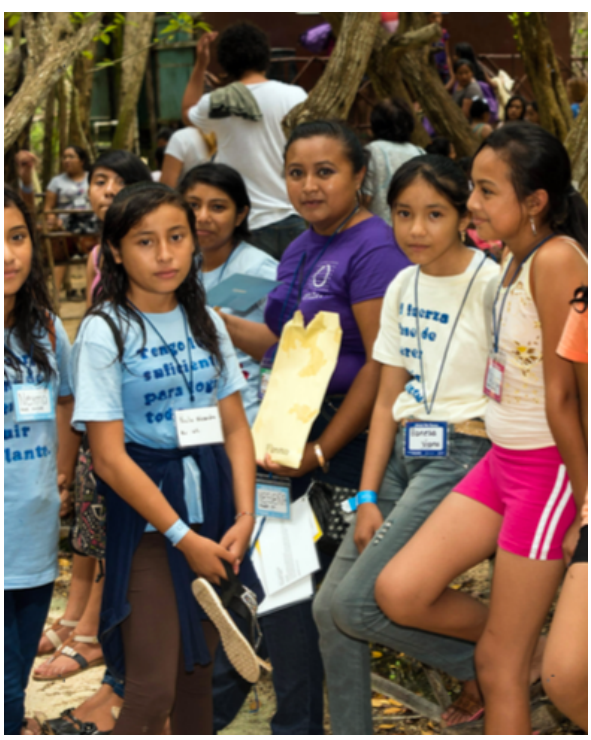

Mentor (center) with Abriendo Futuros participants on excursion to the ecological reserve "El Corchito." Yucatan, 2017

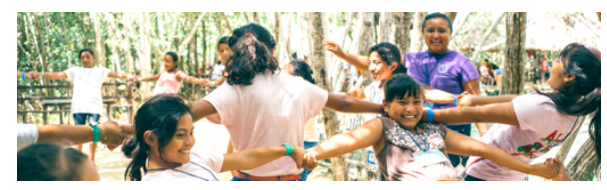

Abriendo Futuros weekly workshop. Yucatan, 2017
The Population Council conducts research and delivers solutions that improve lives around the world. Big ideas supported by evidence: It's our model for global change. www.popcouncil.org

(C) 2020 The Population Council, Inc.
A B R I E N D 0

$F \quad \mathbf{T} \quad \mathbf{U} \quad \mathbf{R} \quad \mathbf{O} \mathbf{S}$

TODAS LAS NIÑAS

TODAS LAS OPORTUNIDADES
POPULATION COUNCIL

Ideas. Evidencia. Impacto. 
youth. ${ }^{7-9}$

Successfully reaching United Nations Sustainable Development Goal 5 to "Achieve gender equality and empower all women and girls" entails pursuing the following milestones: ending all forms of discrimination against women and girls; eliminating all forms of violence against women and girls; eliminating harmful practices such as child, early, and forced marriage; recognizing and valuing unpaid care and domestic work; ensuring women's full and effective participation in and equal opportunities for leadership at all levels of decision-making; and ensuring universal access to sexual and reproductive health and rights, among others.

Rigorous Population Council impact evaluations across world regions (Bangladesh, Ethiopia, Kenya, and Liberia) have shown that girl-centered interventions focused on developing life skills and empowerment have positive results in improving education, sexual and reproductive health, social capital, equitable gender attitudes, and economic empowerment, and in reducing exposure to violence. ${ }^{10}$ All of the above outcomes have been identified as intermediate mechanisms that, together with structural changes in government policies (e.g., economic, education, labor, among others), contribute to achieving gender equality at the individual, household, and community level.

\section{ABRIENDO'S FRAMEWORK}

The Abriendo Futuros (AF) program builds on the Council's global experience of designing and implementing successful girl-centered programs in Africa, Asia, the Middle East, and Latin America and the Caribbean.

\section{FIGURE 1 Yucatan State, Mexico}

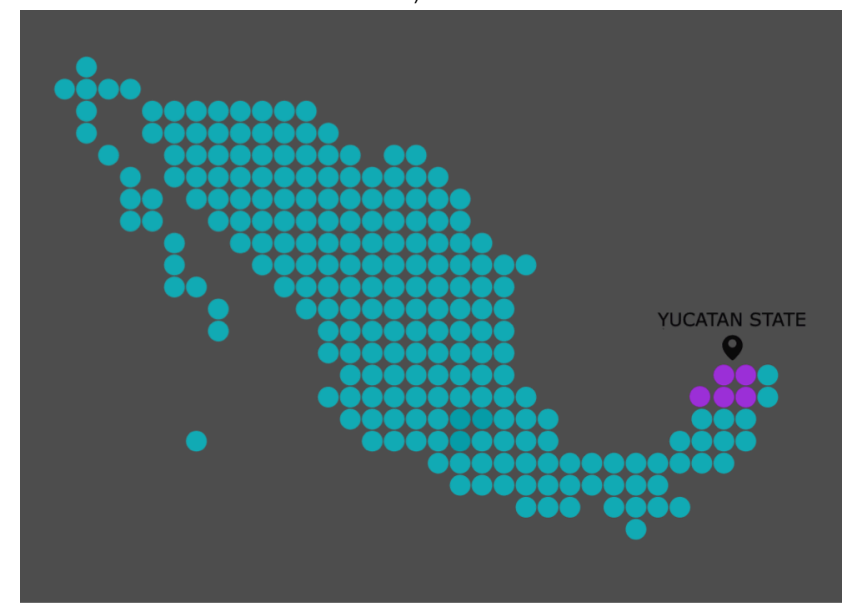

So urce: Created by the authors using AM Charts. Pixel Map Generator. http://pixelmap.amcharts.com

Abriendo aims to improve the living conditions of Mayan girls (10-18 years) and contribute to the achievement of gender equity in the Yucatan. The program's community-focused strategy seeks to empower girls through interpersonal communication and participatory workshops. Girls in selected communities are divided into age groups (10-14 and 15-18) that meet weekly with a mentor in safe spaces. The program's mentors are young women aged 20-30 from the communities, who have been recruited and trained to act as facilitators for the girls. In weekly two-hour workshops, girls learn about sexual and reproductive health and rights, gender equity, prevention of gender-based violence, and financial education, among other topics. This girl-centered approach is supported by an evidencebased design that allows for replication and expansion.

\section{ABRIENDO FUTUROS: PHASE ONE}

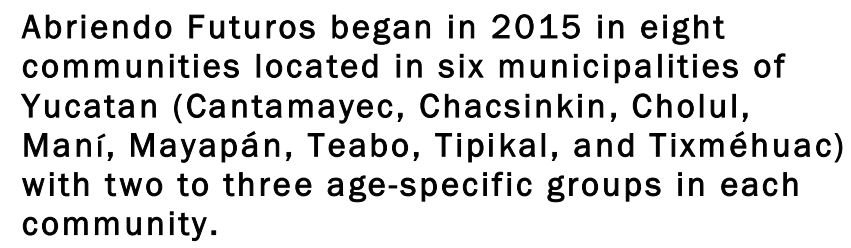

In this initial stage, Abriendo was proposed to bridge the gap between evidence and policy by generating new insights for implementation of a broader state or national program for girls in Mexico.

\section{Research Design}

We used a quasi-experimental design to evaluate program impact, comparing the results achieved in the eight communities that received the program (intervention) with the three control communities. Outcome indicators were related to the rates of school retention, child and early marriage, teenage pregnancy, and other protective assets. ${ }^{11}$ Intervention and control communities were geographically separated to reduce the risk of cross contamination between them.

\section{RESULTS}

The successful two-year pilot phase of Abriendo was implemented from September 2015 to January 2017. Weekly two-hour workshops, taught by mentors in the safe spaces, were divided into six modules (12-14 weeks each).

\section{Program Uptake}

By July 2017, 657 girls had participated at least once in the program out of a total of 1,462 girls aged 10-18 years living in the intervention communities (45\%).

Teabo and Mayapán had the highest number of enrollees (192 and 138 girls, respectively). Tixméhuac had the highest participation percentage increase (93\%) between Module 1 and Module 6, while Tipikal had the lowest (22\%). However, despite the increase in the number of enrollees, only $19 \%$ of adolescent girls had consistent participation (participation in at least $75 \%$ of 
Table 1 Abriendo Futuros communities

\begin{tabular}{ll}
\hline Intervention & Control \\
\hline Cantamayec & Chankom \\
\hline Chacsinkín & Chikindzonot \\
\hline Cholul & Tixcacalcupul \\
\hline Maní & \\
\hline Mayapán & \\
Teabo & \\
Tipikal & \\
Tixméhuac & \\
\hline
\end{tabular}

FIGURE 2 Abriendo Futuros intervention and control communities, Yucatan, Mexico

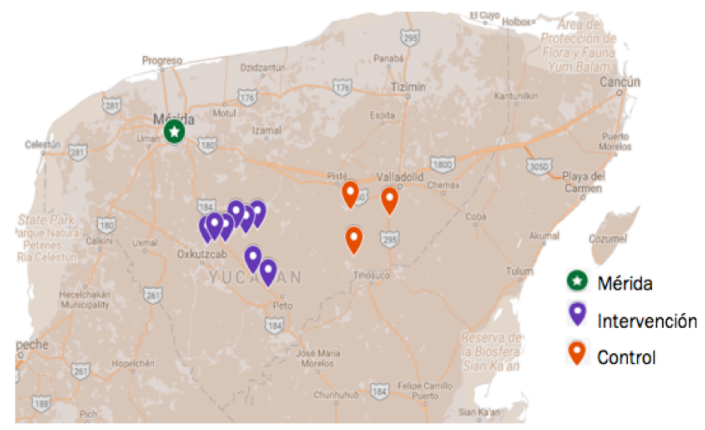

\section{Program Impact}

The impact evaluation showed that the program had positive effects on girls' financial education (having savings in the past three months), sexual and reproductive health knowledge (Family Planning Knowledge Index), and social capital. The Social Capital Index was constructed by adding the following indicators: respondent has friends her own age outside the household, respondent met friends her own age outside the household last week, respondent identifies a mentor, respondent identifies a person who would provide her with a loan during an emergency, and respondent identifies a place where she could sleep during an emergency.

Likewise, the program has had a positive impact on the mentors, as it has supported their professional development, helping them to gain access to technical and university studies. Some of the mentors expressed feeling more empowered when identifying and speaking out against gender-based violence, both experienced by them or by other girls and women in their communities.

\section{Program Challenges}

Even though the program had positive results in outcomes related to protective assets, no statistically significant changes were observed in school retention, child marriage, and teenage pregnancy. The program also experienced several operational challenges. The main challenge was maintaining continuous participation. The highest percentage of nonattendance was observed in adolescents between 15 and 18 years of age. This is possibly due to the fact that the program was not responsive to the specific needs of girls in this age group.

\section{ABRIENDO FUTUROS NEEDS ASSESSMENT}

\section{Qualitative Findings}

A qualitative study was carried out in two of the eight intervention communities. The aim of the study was to identify main problems affecting girls in the communities, as well as opportunities for program improvement. Mentors, girls and boys, teachers, social workers, and parents were interviewed. The reason boys and parents were interviewed was to understand what they perceived were the main concerns for adolescents in the communities.

Girls and boys participating in the qualitative study identified priority needs in their communities as: (1) absence of governmental support (e.g., scholarships) to continue studying; (2) community perceived as insecure (increase of violent incidents); (3) absence of cultural and recreation spaces; (4) lack of decent job opportunities for young people; (5) quality of health services provided; (6) absence of artistic and technical schools in their communities; (7) lack of public transportation; and, (8) barriers to accessing water, food, and electricity. Additionally, $25 \%$ of girls and boys who participated in the study referred to feeling sad in the past month. Parents reported that it was important for their children to continue their studies, which could mean that lack of family support is not the main cause of school dropout in these communities. Mothers mentioned alcohol consumption by their partners as another community issue, as well as absence of mental health services.

\section{Curricular Review}

An external expert carried out a critical review of Abriendo's curricula. Some areas of opportunity for improvement were identified:

(1) Reinforce the modules on rights, gender, and interculturality, which do not fully address the context of inequalities in which Abriendo is implemented and how indigenous communities, specifically indigenous girls and women, experience these inequalities in their daily lives;

(2) Approach the specific contextual needs from a community development perspective, instead of an individual development perspective. Due to the context of deep inequalities present in the intervention communities, we recognize that girls will not be able to enact social change by themselves and that a community development perspective that fosters community integration, problem-solving, selfrepresentation, and promotion of collective action will give girls a better chance of achieving a healthy and productive adulthood versus an individual approach;

(3) Change the sexual and reproductive health education conceptual framework from a biological approach to a holistic sexual education approach that also focuses on the significance and experience of sexuality by girls from a Mayan perspective; and

(4) Include mental health in the curricula. 
The workshop proposed a change to teaching dynamics and methodology to help develop girls' critical thinking and life skills, which will lead them to a more active presence in their communities by contributing to community development as agents of change. Finally, the need to collaborate with other governmental and nongovernmental organizations that are aligned with the overall goal of Abriendo was recognized.

\section{ABRIENDO FUTUROS' ENHANCEMENT: SECOND PHASE}

In the next implementation phase, we restructured the pedagogic proposal of Abriendo Futuros. The curricular enhancements accounted for the challenges identified from the program evaluation, while acknowledging the fundamental need of the program's improvement cycle.

- A participatory meeting was held with mentors and experts in the fields of education, interculturality, and community development to discuss key elements that should be integrated in the proposal.

- The program changed the main focus from empowerment to autonomy, since women and girls in indigenous communities can relate more to the concept of autonomy.

- Autonomy is defined as girls ' progressive achievement of power over their own lives and decisions. It is built on four pillars: (1) knowledge and information; (2) access to material and social resources; (3) freedom of movement; and, (4) establishment of equitable power relationships.

- $\quad$ Strengthen mentors' capacities and competencies through the consolidation of a training proposal that can better respond to the needs of girls and mentors.

- Within this framework, the life skills approach is being reinforced as another fundamental element of the proposal.

- $\quad$ The learning curricula for girls will be built as progressive learning objectives to favor a personal learning progression process in which girls are responsible for their own development. The methodology is enriched by adding a new classification of activities (fixed and variable).

- $\quad$ The program maintains its focus on girls, while integrating an intentional workplan with mothers and fathers, and specific activities where boys will be invited to participate. In this phase, boys will only participate in selected activities in order to discuss topics relevant to both boys and girls, such as

The authors acknowledge Ludivine Cicolella's support in the design of this brief. Suggested citation: F. Romero, Cicolella, L., Larrea, S., Fallone, A., and Vieitez, I. 2020. "Abriendo Futuros." Policy brief. Mexico: Population Council.

(C) 2020 The Population Council, Inc.

Population Council México, Avenida Miguel Ángel de Quevedo 578, Santa Catarina Coyoacán, Ciudad de México. Phone number: +52 1 (55) 84360128.

\section{Soccer team: How the principles of agency were put into action-A program} success story

As a valuable positive consequence of Abriendo

Futuros, the girls from one of the intervention

communities took action and created a soccer team,

reflecting their heightened skills and confidence to achieve

their goals. Sixteen girls participated in the soccer team,

11 of whom regularly attended training and soccer

matches. This activity proved to be a success and showed how girls were able to identify a need in the community and

“What I like from Abriendo is interacting with my girlfriends. Here I found out that it is necessary to support each other. I have also liked the sports activities, for example, soccer. It is one of my favorite parts.... I really like our mentors who have taught us how to get along, how to stick together, how to respect each other."

Building girls' autonomy at the individual level is not possible without engaging the community in advancing equitable gender norms within a framework of historic and social context.

- We frame skills that we want to promote with girls in four thematic areas: (1) comprehensive sexuality education; (2) identity and Mayan culture; (3) human rights and citizenship; and, (4) project management.

- Additionally, a collaborative plan with other governmental and nongovernmental organizations is being created to aid in the generation of personal and professional development opportunities for girls.

\section{REFERENCES}

1. Comisión Nacional para el Desarrollo de los Pueblos Indígenas (CDI). Indicadores Socioeconómicos de los Pueblos Indígenas de México, 2015. CDI. México, 2015.

2. National Institute of Statistic and Geography. Population Census. Mexico, 2010.

3. National Council for the Evaluation of Social Development Policy. Poverty at the municipal level. Mexico, 2015.

4. National Council for the Evaluation of Social Development Policy. Poverty measurement 2008-2018, Yucatan. Mexico, 2018.

5. Hallman, K. et.al. Assessing the multiple disadvantages of Mayan girls: The effects of gender, ethnicity, poverty, and residence on education in Guatemala. Population Council. New York, 2007.

6. National Institute of Statistic and Geography. National Survey of Demographic Dynamics. Mexico, 2014.

7. Yucatan Ministry of Education. Situación de la educación básica en el estado de Yucatán. Panorama 2016-2017. SEGEY. Mexico, 2017.

8. National Institute for the Evaluation of Education. La educación obligatoria en México. Informe 2018. INEE. Mexico, 2018.

9. Yucatan Ministry of Education. School dropout rates. SEGEY. Mexico, 2019.

10. GIRL Center. Delivering Impact for Adolescent Girls. Emerging Findings from Population Council Research. Population Council. New York, 2018.

11. M. Temin, Amin, S., Ngo, T., Psaki, S. How to give adolescent girls voice, choice, and control: A framework for programs focused on empowering adolescent girls. Stanford Social Innovation Review, 2018. 